\title{
Metrópoli y subsunción múltiple
}

\author{
Francisco Quintana
}

Universidade de Barcelona

\begin{abstract}
En este texto se analizan los procesos de fagocitación de comportamientos y subjetividades - subsunción múltiple - en el capitalismo contemporáneo, basado en las tecnologías de la información y de la comunicación, así como en el saber tecnocientífico y social. Se parte de dos premisas: a) el trabajo constituye una relación de poder asimétrica y, además, no es un invariante; b) en las formaciones capitalistas, el trabajo (la fuerza de trabajo) es el único factor que valoriza. A partir de aquí, se constata que ha habido un cambio cualitativo en las coordenadas generales de las formaciones sociales, una de cuyas características estriba en que el nexo valorizante (ley del valor) ha adquirido un difusión sin precedentes. La forma social "metrópoli" - marco general de estructuras y procesos - es la resultante de estas transformaciones. Uno de los rasgos de este nuevo escenario es que en la vertiente socioeconómica "sociofactoría" - se combinan diversas modalidades tecno-organizativas. En él interactúan dinámicas y sistemas, en la indistinción entre lo productivo y lo aparentemente improductivo, que recurren a la captura de comportamientos y de saberes (lenguaje, relacionalidad, esquemas cognitivos etc.) que sobrepasan el reduccionismo del "general intellect" de Marx. Por otra parte, se verifica que la valorización ha devenido relación de poder, política, antes que económica; relación macro y micro; incluye el Estado y el biopoder. Finalmente, destaca, a la contra, la irrupción episódica de fragmentos de espacio/tiempo a modo de "actividad autodeterminada", fractura puntual e impredictible.
\end{abstract}

Palabras clave: Metrópoli, Sociofactoría, Subsunción múltiple, Valorización, Biopoder.

\section{Metropolis and Multiple Subsumption}

This text analizes phagocytosis processes of behaviors and subjectivities - multiple sumbsumption - in contemporary capitalism, which is based on ICT (Information and Communication Technologies), as well as on technoscientific and social knowledge. We start from two premises: a) work constitutes an assymetrical power relationship and, moreover, it is not an stable concept; b) in capitalistic systems, work (labor force) is the only factor in adding value. From here on, we verify that a qualitative change has been produced in general coordinates of social formations, one of which features comes from the fact that value law has seen an unprecedented spreading. The social form "metropolis" - general frame of structures and processes - is the result of these transformations. One of the features of this new picture is the combination of various techno-organitazional modalities in the social and economical aspect. This aspect is worked by systems and dynamics, where there are no distinction between what is called productive and what is not productive apparently, where there is a capture of behaviors and knowledges (language, sociability, cognitive sketches etc.), resulting in the superseding of Marx's reductionism of "general intellect". On the other side, it is verified that the increase in value has become, rather than economical relationship, power or political relationship; macro and micro relationship including the State and biopower. Finally, it is to be emphasized, on the contrary, the episodic irruption of space/time fragments of "self-determined activity", momentary and unpredictable fracture.

Keywords: Metropolis, Social factory, Multiple subsumption, Appreciation, Biopower.

Die arbeit macht frei (el trabajo os hará libres)

Puerta de entrada al campo de concentración de Auschwitz

El poder es frágil, o sea, intranquilo, o sea, dubitativo, o sea, incoherente, o sea, cuestionado, o sea, frágil

J. C. Carrière El círculo de los mentirosos 


\section{Imaginario y ciencia}

Una mirada retrospectiva al debate epistemológico permite constatar que a lo largo del tiempo han surgido, a pesar de todo, diversos argumentos que refutan determinados elementos constitutivos de la visión dominante en la ciencia (Quintana, 1992) - que incluye componentes tales como la presunción de neutralidad y el realismo objetivista -, alguno de los cuales reseñamos sucintamente, esto es:

a) Relación entre saber y poder (Foucault);

b) Imposibilidad de la "prueba empírica exacta" (Heisenberg);

c) Imposibilidad de la "completud" (Gödel);

d) Cuestionamiento del representacionismo (Rorty);

e) Desmoronamiento de las pretensiones de legitimación de la ciencia (Indolencia). ${ }^{1}$

A este conjunto de argumentos podemos añadir otros. Desde el punto de vista que aquí proponemos se considera que la ciencia constituye un tipo de práctica social singular; constructo social e histórico (Latour \& Woolgar, 1988; Woolgar, 1991; Latour, 1992; Burr, 1996); práctica discursiva (Foucault, 1979, pp. 306-307), inscrita en el marco de relaciones de poder, que segrega enunciados que dependen de múltiples determinaciones calificados en términos de "régimen de verdad". Algunas de estas determinaciones consisten en que, al igual que sucede con otros saberes, la ciencia también se halla condicionada por las "verdades prefabricadas", los prejuicios y las creencias míticas que pueblan lo que Castoriadis (1988) ha denominado "magma de significaciones sociales imaginarias", cuya función esencial radica estriba en agrupar, orientar y cohesionar una sociedad. Las "significaciones imaginarias": dios o dioses, ética, polis, democracia, ciudadano, obrero, inmigrante, dinero, Estado, emergen como creación de la propia sociedad, prefiguran las instituciones y hacen que las cosas tengan una significación particular dependiendo del contexto cultural y de la época; una lengua, por ejemplo, no es solamente un sistema de signos para comunicarse, puede ser interpretado, simbolizado también de otro modo, como seña de identidad o como marca. La categorización de estas significaciones como "imaginarias" se debe, aduce Castoradis, a que no tienen una correspondencia con objetos "reales" o "racionales", no "agotan" su significación con la relación establecida con aquellos objetos. Las "significaciones imaginarias" están, pues, en la raíz de la propia institución de la sociedad; fijan un "cerco", una delimitación que afecta a la organización, a la información y al conocimiento; permiten enunciar distinciones esenciales: entre lo que se considera real y lo que no, lo que tiene sentido y lo que carece de él. A este respecto, la ciencia y la técnica, los postulados epistemológicos, el despliegue de conjeturas y refutaciones, en la medida son parte de las prácticas sociales, hunden sus raíces en el orden simbólico instituido y en el imaginario. Sobre este particular, Feyerabend (1981), heterodoxo

\footnotetext{
1 Debido a su interés, vamos a transcribir un extenso fragmento de las Tesis del Colectivo Indolencia (Barcelona, 1986), en que se apuntaban ya algunos elementos que han incidido en lo que constituye la deslegitimación de la ciencia. Dice así: "En los últimos años, la ciencia ha entrado en una crisis de legitimación. Antes gozaba de una elevada valoración por su contribución al progreso y al bienestar general. Hoy, esta aureola de santidad está apagándose a marchas forzadas, a causa de los desequilibrios y desastres naturales que produce. Internamente, la ciencia se legitima mediante la distinción esquemática ciencia pura/ciencia aplicada. La Ciencia, con mayúscula, era presentada como actividad pura, tarea puramente cognoscitiva de un dominio de objetos independientes". "Hoy, esta objetividad, garantía de neutralidad de los productos tecnológicos, se viene abajo. Cada vez es más fácil reconocer el carácter eminentemente tecnológico de la mayoría de las llamadas ciencias puras. Pero, es más; no resulta difícil probar que el aparato conceptual más sofisticado tiene su origen, en última instancia, en ámbitos muy concretos de la práctica humana cotidiana. Y tampoco es algo nuevo decir que la ciencia, sin falsas distinciones de pureza, ha sido el arma del capital - como salto tecnológico - capaz de desarticular la homogeneidad de una composición de clase”. De manera análoga, podemos subrayar las aportaciones críticas de Radical Science Journal, publicadas en los 80, con análisis específicos de determinados enfoques dominantes en la ciencia - caso del influjo ejercido por la Biología Molecular y por la Genética - que han supeditado la elaboración de aspectos básicos de la episteme y de los marcos teóricos a los intereses estratégicos de ciertos sectores del capital (industria química, farmacéutica etc.).
} 
filósofo de la ciencia, puso de manifiesto en el clásico "Tratado contra el método" la similitud existente entre ciencia y mito ${ }^{2}$.

Pues bien, si aplicamos estas consideraciones al tema que tratamos en este texto: las modalidades de subsunción a través de los nuevos sistemas tecnológicos y organizativos en el capitalismo contemporáneo, podremos constatar cómo determinadas nociones profundamente arraigadas y que han formado parte de las cosas que se dan por supuesto conceptuar el trabajo como un invariante en las distintas formaciones sociales - se han mantenido, particularmente en el pensamiento moderno, salvo excepciones, inamovibles. Sin embargo, como tendremos ocasión de comprobar, algunos hallazgos de la etnología, antropología económica y la antropología política han permitido desmontar algunas de aquellas concepciones.

Con todo, en el texto que sigue a continuación analizaremos algunos de los elementos más relevantes de lo que conceptuamos como "subsunción múltiple" fagocitación de la pluridimensionalidad de lo social - en los nuevos formatos que adopta el nexo capitalista, una de cuyas características principales consiste en que se extiende por el territorio e impregna la generalidad de las relaciones sociales para configurar un marco general que engloba a la ciudad, espacial (/temporal), al que denominamos "metrópoli". Para elaborar esta analítica nos apoyaremos en dos premisas que desarrollaremos acto seguido, esto es:

a) Carácter no universal y heterónomo del trabajo;

b) El trabajo (la fuerza de trabajo) es el único factor que valoriza en el capitalismo productivo.

\section{Esbozo genealógico}

Así las cosas, desglosar, aunque sea de manera esquemática, la genealogía del trabajo permitirá establecer una premisa diferenciadora de los enfoques que presuponen, hasta naturalizar, un objeto, el trabajo, que no es más que un conjunto concreto de relaciones dotadas de su propia historicidad.

De inmediato diremos, que, según se desprende de los distintos estudios antropológicos, las formaciones sociales ni siempre ni en todos los lugares han recurrido para satisfacer sus necesidades de alimento, vestido o vivienda a alguna cosa que se corresponda con lo que a lo largo de la historia, en distintas versiones, ha sido definido como trabajo. Tampoco encontramos en el léxico de las diversas culturas palabra alguna que posea aquel significado. Lo que observamos, por contra, es que en varias sociedades primitivas y en algunas sociedades tradicionales se realizan actividades que poseen alguna de las características que tiene el trabajo, como ocurre con la obtención de alimento, pero en estos casos forman parte de los rituales o de las actividades lúdicas y en ningún caso pueden ser calificadas de trabajo. Aquello que se verifica, por tanto, es que en determinadas culturas no existe o no ha existido jamás una categoría o un lexema que englobe las propiedades que habitualmente se atribuyen al trabajo: obtención de bienes para satisfacer necesidades, esfuerzo, sacrificio, aunque también imposición externa. Podemos decir que en su léxico no aparece el término para designar las prácticas que en otras formaciones socioculturales se consideran productivas, porque que la satisfacción de necesidades se concibe de otro modo, o

2 Desde la perspectiva de la analítica del discurso, Dijk (2003) ha subrayado cómo los aspectos cognitivos y la discursividad, lo que incluye a la ciencia, en la medida en que son prácticas sociales están insertos en una trama de relaciones ideológicas y de poder. 
para ser más exactos, debido a que su comportamiento obedece a un tipo de lógica distinta a la racionalidad productivista - que persigue el incremento ilimitado de riqueza - surgida a partir de cierto momento de la historia moderna en los procesos sociales y económicos. Como ha subrayado P. Descola, aquellas culturas no poseen: "...la idea de un conjunto coherente de operaciones técnicas destinadas a producir todos los medios materiales necesarios para la subsistencia. El idioma tampoco dispone de palabras que designen los procesos de trabajo en sentido amplio como la pesca, la horticultura o la artesanía; nos enfrentamos, por tanto, al problema de comprender unas categorías indígenas que delimitan los procesos de trabajo de un modo muy diferente al nuestro (...) El lexema indígena cuyo campo semántico más se asemeja a uno de los usos actuales de la palabra "trabajo" es "takat" (...), palabra que se refiere a una actividad física, penosa, que requiere conocimientos técnicos y la mediación de una herramienta" ${ }^{3}$.

En algunos casos sí que existe el lexema trabajo, pero su significado es distinto, designa actividades como el tiempo de reflexión del chamán de la Amazonia, que, sin duda, no pueden ser adscritas a ninguna de las propiedades asignadas al trabajo. Lo que apreciamos en las culturas que poseen dicho término es que su campo semántico es muy amplio y aglutina prácticas que no se corresponden con aquellas que configuran el espacio homogéneo de lo que entendemos como trabajo. Por otra parte, en los casos en que el léxico no incluye aquel término, pero si algunas de sus características, como esfuerzo y sufrimiento, tales rasgos no indican la existencia de vinculación alguna con lo que serían prácticas productivas encaminadas a la satisfacción de necesidades y, por este motivo, constitutivas de la noción de trabajo.

Estas indagaciones muestran, pues, claramente, que el trabajo entendido como una clase de relación que incluye sobre todo ciertas propiedades que le convierten de manera explícita en instrumento para la obtención de determinados bienes básicos, no constituye ningún universal. Los estudios etnológicos y en antropología demuestran que en las sociedades primitivas, nómadas o sedentarias, no existía aquel tipo de relaciones, y que en los casos en que existía el lexema trabajo no servía para designar las actividades de transformación necesarias para satisfacer necesidades. A este respecto, cuando M. Sahlins (1983) se refiere a las sociedades de cazadores y recolectores no las considera "sociedades de subsistencia", sino "sociedades opulentas", debido al poco tiempo que dedican a la obtención de los bienes necesarios ya que son sociedades austeras. Por su parte, Clastres (1978, 1981, 1986), en contraposición a lo que califica de economicismo de los etno-marxistas, representado por Meillassoux y Godelier, conceptúa también a las sociedades primitivas contemporáneas (Melanesia, Vietnam, América del Sur etc.) como "primeras sociedades de la abundancia".

Siguiendo el hilo conductor genealógico, nos referiremos en este punto a las culturas griega y romana, y haremos hincapié en la distinción que efectúa Arendt (2001) entre labor, trabajo y actividad, condiciones esenciales del ser humano englobadas en la denominada "vita activa". El término labor abarcaría las actividades del cuerpo humano en tanto que organismo biológico, en el que desarrollo y decadencia están ligados a necesidades vitales. En cambio, el trabajo es la actividad que correspondería a "lo no natural" en el ser humano; el trabajo aporta un mundo artificial de cosas, distinto al de las cosas naturales. Finalmente, la acción, manifestación de la condición humana, es la única actividad que tiene lugar sin la intervención de cosas o de materia; pertenece a la esfera de la pluralidad, y debe su existencia a que los hombres, esos seres concretos, habitan el mundo; aquí la pluralidad en tanto que característica de la acción es la condición de cualquier vida política. Asimismo, si se toma como referencia Locke, por un lado estarían las manos que trabajan y, por otro, el cuerpo que labora. Esto remite a la diferenciación establecida por los griegos entre los "cheirotechnes" o

3 Descola Société avec e dans concept de travail: remarques anthropologiques en Sociologie du travail, número extra, 1994, citado por Méda (1998), p. 28. 
artesanos, que son los que trabajan manualmente, y los "to somati ergazesthai", expresión que designa a los esclavos y a los animales domésticos, que son los que laboran con sus cuerpos para satisfacer las necesidades básicas. A este respecto, según Arendt, existe acuerdo para afirmar que ni en su acepción antigua ni en la moderna los términos labor y trabajo son sinónimos. La palabra labor, a diferencia de lo ocurrido con el término trabajo, nunca se refiere a un producto acabado, únicamente alude al proceso que le antecede. De todos modos, lo que se constata en cualquier caso es que en Grecia y Roma tanto la labor como el trabajo eran considerados algo despreciable. El menosprecio hacia la labor nacía del deseo de alcanzar la libertad, de superar todo lo que significara estar atado a las necesidades, de la desaprobación de todo esfuerzo que no deja huella, que no produce monumento ni obra artística capaz de pasar a la posteridad. Entre los griegos el artesano tampoco estaba valorado, como un reflejo del rechazo de la mentalidad propia del "homo faber". Asimismo, no deja de ser significativo que en la cultura romana la etimología de la palabra trabajo tenga que ver con el término "tripalium", instrumento de tres patas empleado para torturar a los esclavos desobedientes.

Con todo, esta concepción negativa del trabajo se prolonga durante un parte del medioevo. No hay que olvidar que para la tradición cristiana el trabajo era un castigo por no haber acatado la voluntad divina. Sin embargo, en el siglo VI se produjo un cambio importante. Benito de Nursia, rompiendo con la tradición que estigmatizaba el trabajo, instituye en la vida monástica el hábito de combinar oración, recogimiento y laboriosidad, tal y como se desprende de la expresión "ora et labora". Las repercusiones de este cambio en el ámbito de la cristiandad traspasaron con el tiempo el microcosmos que representaban los cenobios. En el siglo XIII, Tomás de Aquino añade un nuevo ingrediente a este cambio al considerar legítimo el lucro si es fruto del trabajo y los resultados son cosas útiles para la sociedad. Posteriormente, en los siglos XV y XVI, Lutero y Calvino se convirtieron en adalides de esta nueva manera de ver las cosas al mezclar religiosidad y laicismo. A este respecto, el calvinismo concibió la vida como algo predeterminado por el poder divino, y subrayó, como un elemento con notable impacto en lo económico, la importancia de tener una vida laboriosa y sobria.

Finalmente, en el siglo XVIII, en los albores de la Primera Revolución Industrial, cuando nace la economía como ciencia, se instaura la noción productivista del trabajo; concebido en tanto que dispositivo cuya finalidad estriba en la producción creciente y sin límite de mercancías. Según Naredo (1997), estas fueron las coordenadas que hicieron posible esta transformación:

a) Se tuvo que difundir entre la población el credo de que acumular riquezas no atentaba contra las convicciones morales de los individuos;

b) Se vio modificada la noción de riqueza para hacerla compatible con el afán de acumulación;

c) El ser humano tuvo que ser considerado un factor capaz de generar riqueza;

d) El trabajo fue conceptuado como el principal instrumento para la creación de riqueza.

Un aspecto a destacar es que, por lo que se refiere a las instituciones, los rasgos esenciales de aquellas concepciones se han mantenido hasta la actualidad. A pesar de todo, es necesario subrayar que estos cambios no han transcurrido sin resistencias que han evidenciado el carácter de extrañamiento e impositivo, de un modo u otro, del trabajo. Imposición, pues, de un vínculo que con el capitalismo productivo separa al sujeto artesano, campesino - de las relaciones autóctonas, precedentes, para convertirle en "trabajador libre". En cuanto a las dificultades de este proceso, el propio Weber (1993) pudo constatar que, como un síntoma palpable de la ausencia de ambición por acumular riquezas de los obreros alemanes a fines del siglo XVIII, no era inusual comprobar que la pregunta que 
se hacían era: icuánto debo trabajar para ganar 2,50 marcos que recibo actualmente y que cubren mis necesidades?, y no icuánto puedo ganar diariamente si realizo el máximo trabajo posible?

Este interesante descubrimiento de Weber no es, sin embargo, una excepción. En la historia del movimiento obrero de los últimos tres siglos aparecen multitud de pruebas que corroboran un tipo de subjetividad que incluso va mucho más allá; en las resistencias surgidas el día a día del trabajo a domicilio o, posteriormente, en la "gran fábrica"; en las luchas masivas que se sucedían periódicamente en las fábricas; signos de rechazo: apropiación de materia prima, sabotajes... ante lo que significaban las condiciones de vida, el expolio, instaurado por el capitalismo productivista. Un ejemplo de lo que decimos fue la destrucción de máquinas protagonizada por los ludditas, que en realidad no fueron, a pesar de las tergiversaciones, luchas contra las máquinas o contra el avance tecnológico, sino manifestaciones de indignación y rechazo de las consecuencias sociales de las aplicaciones tecnológicas en el contexto expansivo del capitalismo del "laissez faire" con un aumento brutal de la explotación y de la miseria. No es casual, por otra parte, como algo representativo de la no aceptación de la disciplina laboral, que palabras como "carda", que servía para designar la herramienta con la que antes del maquinismo se realizaba la operación de cardar, significara en lengua castellana amonestación y paliza. Asimismo, en lengua catalana hay una acepción según la cual dicho lexema significa estar mal ${ }^{4}$.

En el siglo XX, con el trabajo fordista (en cadena) y el taylorista (basado en la fragmentación de tiempos y movimientos) tiempos del "obrero masa", obrero de la cadena de producción, se da una situación paradójica, de rechazo y aceptación, con respecto al trabajo. En efecto, el trabajo, o mejor, el trabajo vivo - actividad en proceso de incorporación al objeto mercancía - fuente de valor para el capital y del que es depositaria una masa relativamente homogénea de trabajadores, ha tenido para el movimiento obrero una significación ambivalente. Por una parte, como valor, como identidad cultural; en cambio, por otra parte, tanto en lo macro, con la huelga, la interrupción del flujo valorizante, la indisciplina, como en lo microsocial, mediante el absentismo, el sabotaje etc. constituyó un instrumento para la lucha económica y política privilegiado. En este sentido, los ciclo de lucha en diversos países industrializados, en los 60 y 70, ilustran la capacidad deestructurante de esta "centralidad obrera". Sin embargo, con la reestructuración, Tercera Revolución Industrial, la Segunda fue la fordista y taylorista, se clausura un periodo cuyo balance más significativo ha sido la derrota de la "centralidad obrera" - desarticulación de determinada composición social y política - y el fin de una ontología y de un sujeto considerado portador de un proyecto histórico de transformación radical (Quintana, 2002b, p. 169).

Podemos concluir, pues, que lo que muestra esta genealogía es que el trabajo no ha constituido ninguna invariante en las distintas culturas y formaciones sociales. Y, cuando aparece, está cargado de connotaciones simbólicas negativas, asociadas al sacrificio y al dolor; además, como nexo social se prefigura, de un modo u otro, como imposición, como relación heterodeterminada. Por otra parte, hay que recalcar también que la difusión del trabajo como relación social que interviene en los procesos de transformación socioeconómica en el periodo correspondiente al capitalismo productivo, cuyo resultado es un objeto que satisface determinadas "necesidades históricas", comporta, en general, una profundización de todos estos rasgos. En cualquier caso, su etimología latina que liga la palabra trabajo al latín "tripalium" no permite albergar ninguna duda sobre este particular.

4 En relación con esta temática, desde una óptica que vincula técnica, trabajo y relaciones sociales, como muestra atípica que contrasta con fetichización generalizada que invade la esfera de lo tecnológico, ver también: Mumford (1967, 1982, 2002), Noble (1984, 2001), Quintana (2002a) e Ellul (2003). 


\section{Capital, trabajo y valorización}

Tras este apretado periplo, que ha posibilitado establecer la primera premisa, es decir, describir algunas de las principales características del trabajo en sus diversas modalidades: heteronomía, no universalidad etc., procederemos a formular la segunda premisa. Ésta consiste en enunciar algo que nos resulta familiar, a saber: que en el circuito de la mercancía la fuerza de trabajo es el único factor capaz de incrementar el valor del capital, de valorizar, en el capitalismo productivo, tal y como puso de manifiesto Marx (1972, 1974, 1978, 2001) en los textos dedicados a la "crítica de la economía política" del capital. Es preciso puntualizar, sin embargo, que en este apartado nos limitaremos a exponer de manera simplificada la versión marxiana de la relación entre trabajo y valor, sin adentrarnos, por el momento, en la controversia acerca de la teoría del valor en el postfordismo.

Así pues, una ojeada a la historia económica nos permite comprobar, como ha subrayado Guerrero (1997), que una de las cosas que compartieron fisiócratas, clásicos y Marx, pero no los neoclásicos - corriente que con paso del tiempo se ha convertido en la "gran ortodoxia", dominante en la actualidad - fue la preocupación por indagar cómo transcurría la generación, extracción y distribución de excedente. Por otra parte, aunque la respuesta a aquel interrogante por parte de los clásicos y de Marx consistió en atribuir al trabajo la clave del valor, no obstante, fue este autor quien abordó con mayor rigor la complejidad fenoménica del nexo capitalista. En los párrafos que siguen a continuación expondremos el proceso demostrativo del papel de la fuerza de trabajo como el factor valorizante, piedra angular del crecimiento capitalista, de la reproducción ampliada.

A este respecto, si tomamos como punto de partida el análisis marxiano, observaremos que las fases que sigue el desarrollo económico, empezando por el capitalismo mercantil, en el que simplemente la mercancía se vende a un precio superior al de su adquisición, se intercambia dinero (D) por mercancías (M) para obtener más dinero ( $\mathrm{D}^{\prime}>$ D), pueden esquematizarse como sigue ${ }^{5}$ :

$$
\mathrm{D}-\mathrm{M}-\mathrm{D}^{\prime}
$$

Sin embargo, en el capitalismo productivo, basado en el vínculo entre capitalista y obrero asalariado, el proceso cambia para mostrar unos rasgos sin precedentes que representamos de este modo:

$$
\mathrm{D}-\mathrm{M}(\mathrm{MP}, \mathrm{FT}) \ldots \mathrm{P} . . . \mathrm{M}^{\prime}-\mathrm{D}^{\prime}
$$

En este caso hemos incluido nuevas variables: medios de producción (MP), fuerza de trabajo (FT) y producción (P). Es posible también representar el proceso de crecimiento y

\begin{tabular}{|c|c|c|}
\hline transacción/circulación & producción & transacción/circulación \\
\hline 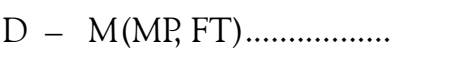 & $\mathrm{P}$ & ............................ \\
\hline $\mathrm{D}^{\prime}-\mathrm{M}^{\prime}\left(\mathrm{MP}^{\prime}, \mathrm{FT}^{\prime}\right) \ldots \ldots \ldots . . .$. & $\mathrm{P}^{\prime}$ & $\mathrm{M}^{\prime \prime}-\mathrm{D}^{\prime \prime}$ \\
\hline $\mathrm{D}^{\prime \prime}-\mathrm{M}^{\prime \prime}\left(\mathrm{MP}^{\prime \prime}, \mathrm{FT}^{\prime \prime}\right) \ldots \ldots \ldots$ & $\mathrm{P}^{\prime \prime}$ & 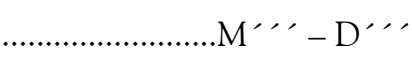 \\
\hline
\end{tabular}
acumulación de capital de un modo que refleje con mayor detalle su complejidad:

5 Para la realización de este apartado hemos utilizado principalmente los texto de Marx El Capital, vol. 1 (1972, pp. 891-995), Teorías sobre la plusvalía (1974) y Cuadernos Grundrisse (1978), así como, aunque con modificaciones, algunos esquemas elaborados por Guerrero (1997). 
Una particularidad de estos procesos en que $\mathrm{D}^{\prime \prime}>\mathrm{D}^{\prime \prime}$, y $\mathrm{D}^{\prime \prime}>\mathrm{D}^{\prime}$ es que al final hay más valor que al principio; diremos que ha habido valorización. A este respecto, el aumento del valor debido a la generación de excedente que se da entre el principio y el fin, entre, por ejemplo, D y D', debe tener una causa, y ésta necesariamente tiene que estar en $\mathrm{P}$, puesto que $\mathrm{D}$, el dinero, sistema de signos vertebrado por una relación de poder asimétrica (capitalista/obrero o capital/trabajo necesario-trabajo excedente), no tiene por sí mismo capacidad de valorizar. D es el correlato simbólico - "medio de pago" - constructo que refleja con mayor o menor fidelidad (por ejemplo: situación inflacionaria) la riqueza existente y, sobre todo, como ha subrayado Negri $(1979,2003)$, relación de poder que pone de manifiesto el antagonismo que entraña el nexo capital-trabajo, vínculo fundamental entre plusvalor social(perspectiva del capital)/trabajo excedente(perspectiva obrera) y trabajo socialmente necesario. Así pues, si examinamos $\mathrm{P}$ comprobaremos que el valor de MP es transferido de manera fraccionada en su totalidad a las mercancías terminadas, $\mathrm{M}, \mathrm{M}^{\prime}$... distribuyéndose entre todas ellas. Queda FT que tiene una propiedad y es que puede producir más valor del que corresponde al valor que se precisa para lograr su reproducción. Por consiguiente, hay que concluir que es en FT donde reside la capacidad de producir excedente, de producir plusvalor, condición indispensable para que tenga lugar la reproducción ampliada de capital. Sobre este particular, hay que destacar que con el marginalismo, que elude el análisis de los procesos que tienen lugar en $\mathrm{P}$, se abre una brecha insalvable entre los neoclásicos y sus herederos neoconservadores con respecto a otras interpretaciones (neokeynesianas, regulacionistas).

Por último, es preciso hacer hincapié en que para dilucidar el significado de $\mathrm{D}$ o el del capital y el de $\mathrm{P}$ hay que partir del valor y, más en concreto, del valor de cambio en la circulación, y no del trabajo, puesto que el trabajo, considerado habitualmente el fundamento del valor, solamente puede transformarse en capital " si el mismo es incorporado en la forma del intercambio, en la forma del dinero” (Negri, 1979, p. 77). El corolario de este razonamiento es que antes que ser un reflejo del monto de la riqueza lo que indican estos procesos es la existencia de una relación de poder/resistencia/antagonismo subyacente.

Por otra parte, que duda cabe que un postulado en este tipo de axiomática es que para el capital carece de sentido, y este es un elemento esencial, estructural, de la crisis, involucrarse en un proceso en que no aumenta de manera creciente el volumen de capital y su valor, lo que podemos representar así:

$$
\mathrm{D}-\mathrm{M}-\mathrm{D}
$$

En cambio, este postulado sí se incumple en la relación contractual y de intercambio establecida entre capitalista y trabajador, en que el salario obtenido corresponde al coste de la mercancía fuerza de trabajo, que es el coste de su reproducción, pero no al valor de lo producido por esa misma fuerza de trabajo, que es a fin de cuentas el valor global del trabajo efectuado. Esta sería la representación esquemática de dicho proceso:

$$
\mathrm{M}-\mathrm{D}-\mathrm{M}
$$

En cualquier caso, la implantación de la axiomática productivista, valorizante, a la generalidad de las estructuras y procesos a resultas de la "gran transformación" que se inicia en los 70 - reestructuración de los sectores, mundialización y financiarización económicas englobando múltiples ámbitos - industrialización de la agricultura (agricultura intensiva), industrialización de los servicios (logística, servicios informáticos, turismo etc.), pero también de determinadas prácticas sociales (socialidad, comunicación etc.) que estaban al margen de esta mercantilización - hace que tengamos que aplicar los componentes esenciales de aquel esquema - la fase $\mathrm{P}$ - de manera genérica a los comportamientos y relaciones sociales.

Hasta aquí, por tanto, la segunda premisa de este excursus que podemos resumir afirmando algo que no es completamente nuevo, pero que con frecuencia se distorsiona esto 
es: que el trabajo o la contribución de la fuerza de trabajo es el único factor que valoriza en el capitalismo productivo, tal y como se deduce de la teoría del plusvalor, pieza fundamental del corpus marxiano, aunque también de cualquier interpretación crítica del funcionamiento de la economía del capital.

\section{Fordismo, crisis y postfordismo}

Llegados a este punto, nos referiremos a las características del fordismo y del taylorismo y de su relación con el conflicto social, situación que finalmente desemboca en el escenario actual, uno de cuyos principales efectos ha sido la mutación del trabajo. En este sentido, el "método topológico" propuesto por Coriat (1982) para analizar los cambios sociales y en particular la transformación de la fábrica fordista (y taylorista), diferenciado del mero seguimiento fenomenológico de las secuencias históricas, hace posible vislumbrar los cambios técnicos a partir de las figuras contrapuestas del poder y de la resistencia. Permite asimismo esclarecer la crisis y obsolescencia de ciertas modalidades del trabajo industrial, sobre todo en las áreas centrales del capital; caducidad de una modalidad de organización de la producción y de la vida laboral en que la fábrica y el trabajo eran lo que daba sentido a la vida del asalariado.

Así, al examinar la etapa fabriquista es posible verificar cómo el "Scientific Management" (SM) de Taylor fue, en la segunda década del siglo XX, el instrumento crucial para acabar con la autonomía que poseía el trabajador de oficio, depositario de específicos saberes operativos. Se trataba, según la jerga tayloriana, de terminar con la "holganza obrera sistemática". Que duda cabe, la organización taylorista del trabajo y la cadena fordista, cinta sinfín, permitieron remontar la crisis sin alterar las reglas de juego de un mercado cada vez más monopolista. La aplicación de la "Organización Científica del Trabajo" (OCT) a través del SM tayloriano, que parametriza y fracciona cual microfísica los movimientos y operaciones, y la cadena fordista, convierten las secuencias de la producción en un circuito sin fugas improductivas. Se configura de este modo la "forma moderna de la acumulación", de la producción en masa, homogénea y standarizada. Diseño que desemboca, finalmente, en ese formato estable basado en una mezcla de "keynesianismo" y "pacto social" en virtud del cual el obrero comparte con el capital las ganancias de productividad a cambio de paz social, es decir, de la renuncia a la lucha.

La implantación de la cadena fordista y taylorista comportó un triple proceso:

a) Separación entre trabajo de concepción y ejecución de tareas;

b) Parcelación extrema y rutinización de las operaciones de concepción y ejecución;

c) Standarización de los productos y prolongación de las series.

Estos procesos se combinaban en una cadena caracterizada por la parcelación y repetición rutinaria. En ellos se impusieron demostrando una gran efectividad los tres principio taylorianos básicos:

a) Las funciones en el proceso de trabajo se especializan;

b) Fraccionamiento de las tareas (movimientos, operaciones etc.);

c) Medida de tiempos y movimientos.

A partir de cierto momento, en la segunda postguerra, estas técnicas dieron un paso importante al introducir la "segunda generación" de sistemas de racionalización. Así, la implantación de las tablas Motion and Time Measuring (MTM) favoreció notablemente la 
capacidad productiva: aumenta la cantidad de mercancías elaboradas y la eficacia en la utilización de la fuerza de trabajo. En esta tesitura, la crisis del fordismo y del taylorismo se tradujo en crisis de la OCT, considerada hasta después de la Segunda Guerra Mundial el método más eficaz y seguro para asegurar el crecimiento económico. Dos elementos explicarían esta situación (Coriat, 1982, p. 146):

a) Dificultad desde mediados de los 60 de asegurar las ganancias de productividad económica y social;

b) Agotamiento por diversas causas del modelo fordista y taylorista como fundamento de la valorización.

A ello habría que agregar una serie de signos visibles de la crisis. Primero, la ausencia de un relevo técnico y organizativo capaz de reemplazar al fordista y taylorista. En segundo lugar, la introducción de otros métodos y otras máquinas de la mano de la "ingeniería organizacional" y la difusión de la electrónica y la microelectrónica comportaron un "agravamiento de la composición técnica y de la composición del valor del capital". Por último, sucedió que la nueva composición técnica y orgánica requería para ser rentable prolongar las series, lo cual traía aparejado, por el contra, la desvalorización del capital.

Con este panorama, el cambio en las técnicas de fabricación, pero sobre todo en las formas organizativas para "superar" la crisis provocaron, sin duda, una modificación sustancial del estatuto del trabajo. Sin embargo, hay que recordar que ya en los 50, mucho antes de que Volvo patentara el "sistema kalmariano" (basado en el trabajo cooperativo en grupos autónomos, no jerarquizados y con fuerza de trabajo cualificada, supeditados al ritmo que fija la cadena), EEUU y Japón habían comenzado a experimentar formas organizativas que con el paso del tiempo darían lugar a los "equipos multidisciplinares toyotistas" (agrupaba en un equipo "holístico", responsable de la totalidad del producto, diversos tipos de cualificación: obreros cualificados, ingenieros etc. inmersos en una dinámica impuesta de innovación permanente o "kaizen") a los "GTs" (grupos de trabajo dependientes de una relación jerárquica autoritaria) de General Motors y Nissan. No obstante, en aquellos años el marco conceptual todavía no se había visto modificado, condición que sí se cumple en los 70, puesto que en esta década tiene lugar la reestructuración monetarista y neoliberal, lo que comporta el relevo del fordismo y taylorismo como concepción global predominante de la organización del proceso productivo; lo que ha tenido, que duda cabe, importantes repercusiones en distintos aspectos: relación entre fuerza de trabajo y proceso productivo y reproductivo, utilización de sistemas tecnológicos, papel del conocimiento etc. Podemos concluir, por tanto, que a partir de ese momento sí se puede hablar de "nuevo de paradigma" tecnológico y organizativo. Con todo, esto no va a suponer la desaparición de todos y cada uno de los ingredientes del fordismo y del taylorismo, ya que algunos de ellos van a ser reutilizados masivamente, pero con otra matriz.

Por otra parte, es preciso subrayar, asimismo, que tanto en la crisis del "modelo fordista", uno de cuyos signos más palpable fue la desvalorización del capital, como en la reestructuración, incidieron diversos factores. En este parágrafo trataremos el que podríamos considerar como principal factor, ya que es el núcleo activador del incremento, o bien del decrecimiento del valor, a saber: evolución de la "asociación disociante" capital-fuerza de trabajo social. Sobre este particular, Aglietta (1979), al analizar estos procesos, ha señalado que entre el fin de la Segunda Guerra Mundial y mediados de los 60 fue posible el alza relativamente continuada del salario real debido a la baja continua del coste salarial social real puesto que plusvalor aumenta, lo que podría explicar la impresión de que el consumo estaba dinamizando la producción de bienes de consumo. Ahora bien, con el agravamiento de las luchas obreras en contra de la parcelación y de la intensificación repetitiva del trabajo se empezaron a percibir los límites en el alza del plusvalor ya que se incrementan los costes del salario social real. Se rompe, así, el eventual equilibrio mantenido a lo largo de dos 
décadas; ruptura de las condiciones derivadas del pacto por parte de las fuerzas portadoras del trabajo vivo que tuvo sus momentos álgidos entre la segunda mitad de los 60 y los 70 . Una figura clave que contribuyó a esta situación fue el trabajador de la cadena. Este trabajador, "obrero masa", que se gesta a finales de la primera Guerra Mundial y se consolida con el New Deal roosveltiano que promueve las grandes concentraciones industriales y expande el consumo, fue justamente quien protagonizó los ciclos de lucha de los 50 y 60 .

Con todo, los comportamientos resistentes o, en algunos casos, claramente ofensivos: huelgas salvajes, sabotajes, absentismo etc. eran la prueba de que en periodos concretos, detrás de la mera cuestión salarial, de la mejora en el precio de la mercancía fuerza de trabajo, estaba la refutación práctica de un "contrato social", de lo que la interpretación foucaultiana calificó de "aulario microfísico". Sobre este particular, hay que decir que en las luchas de los trabajadores del sindicato Industrial Workers of the World en los orígenes del fordismo norteamericano, descritas por Dos(1983) y Adamic (1984), ya se aprecian muestras de aquel tipo de comportamientos, que, pasados algunos años, volvemos a encontrar en el "obrerismo" de la segunda postguerra. A este respecto, diversos autores, entre los que cabe destacar: Alquatti (1977), Gorz y Marglin (1977), Bologna (1978), Heinz (1979) y Tronti (2001), han remarcado la estrecha conexión existente entre conflicto obrero, caída de la tasa de beneficios del capital y cambio tecno-organizativo del trabajo de acuerdo con las secuencias: conflicto-antagonismo-crisis-reestructuración. Desde esta óptica, el conflicto y la crisis son elementos que inciden en ese instrumento de gestión de la crisis que es la innovación tecnológica y organizativa.

En definitiva, el salto tecnológico y la renovación de las formas de organización, la implantación no sistemática del postfordismo: Tecnologías de la Información y la Comunicación (TIC), saber tecno-centífico, saber social difuso... y del neofordismo: fordismo sin garantías sociolaborales... (que categorizamos genéricamente como neo/postfordismo) fue la respuesta a la crisis del fordismo y del taylorismo en cuya génesis estaba la propia crisis de la funcionalidad del "obrero masa"; y, más en general, la ruptura de un contrato no escrito que se sustentaba en la aceptación de la disciplina panóptica a cambio de participar en los beneficios de los aumentos de productividad por la vía del salario real directo o del indirecto (welfare etc.). Efectivamente, antes de la reestructuración, ocupación, trabajo y salario eran los referentes de la "centralidad obrera"; núcleo activador de los procesos de agregación reivindicativa y antagonista; elementos que articulaban la composición técnica (organización del trabajo, capital fijo...) y política (comportamientos resistentes...). Después, tras la derrota, se pasa pagina a lo que había sido la fábrica fordista y taylorista. Con este giro copernicano, el contexto se ve modificado y la producción se prefigura como "producción integral", caracterizada por el hecho de que las diversas esferas: producción, circulación, reproducción, aparecen vertebradas por la racionalidad valorizante.

Así pues, con el paso al neo/postfordismo, el trabajo, en el que persisten procedimientos fordistas y tayloristas modificados - neofordismo y neotaylorismo - ve alteradas algunas de sus propiedades. El trabajo se flexibiliza, se torna versátil, pierde la rigidez normativa y jurídica que había tenido; si, por un lado, deja de ser referencia axiológica y política, por otro, desde el punto de vista del contenido del circuito de la mercancía, se extiende por el territorio, sobrepasa la fábrica, hasta saturar de criterios productivistas el nuevo escenario - ciudad-empresa y del control - que categorizamos como "metrópoli". 


\section{Postfordismo y neofordismo}

Con el vuelco postfordista cambia sustancialmente la manera de concebir el circuito productivo integral y, más concretamente, el trabajo y los dispositivos tecnológicos y organizativos. A pesar de todo, se mantienen, aunque con algunos cambios, en determinadas áreas geográficas, sectores y segmentos, aplicaciones que remiten al fordismo y taylorismo, adaptadas al régimen flexible de acumulación, y que aquí conceptuamos de neofordistas. Esto quiere decir que poner el acento exclusivamente en las actividades postfordistas sin tener en cuenta la presencia masiva de trabajo neofordista (y neotaylorista), como sucede con los teóricos del "ciclo de producción inmaterial" y del "capitalismo cognitivo", conduce a una imagen distorsionada de estos procesos. Sin duda, el aspecto que ofrece el entramado sociolaboral y de la producción es mucho más complejo. En él observamos un amplio abanico de "asalariados a la carta" (Deliri, 2004), "contingent jobs", puzzle multiforme en el se alternan: trabajadores cognitivos, trabajadores cognitivo precarios, asalariados neomanchesterianos, "working poor".

Por otra parte, es preciso resaltar cómo estas transformaciones han configurado la morfología del territorio; la huella espacial (y temporal). Efectivamente, como señaló Gaudemar (1981), la remodelación del espacio productivo ha transcurrido según un doble movimiento aparentemente divergente. Por una parte, al tender hacia la concentración espacial conformando alguna modalidad de "gran fábrica" en una etapa concreta de su desarrollo; lugar de entrecruzamiento e interconexión de diversos procesos productivos o de ensamblaje. Además, al potenciar la deslocalización y el "outsourcing" (externalización de ciertos procesos: segmentos de la línea de producción, servicios informáticos, seguridad etc.), lo que implica la recuperación de formas tradicionales, periféricas de trabajo: taller rural, trabajo a domicilio, taller clandestino; el telemarketing y las "maquilas", aunque distintos en algunos aspectos importantes, serían dos ejemplos representativos de estos formatos y de la difusión por el territorio de las relaciones sociales de trabajo y mercantilizadas que conllevan el postfordismo y el neofordismo.

Desde el ángulo del urbanismo, Harvey $(1995,1998,2000)$ ha remarcado también el papel crucial del espacio(/tiempo) al afirmar que el régimen de acumulación flexible hace todavía más necesario el dominio del territorio en tanto que requisito del proceso de acumulación ampliada. Hay un estrecho vínculo de subordinación de los "fenómenos urbanos" con respecto a racionalidad valorizante. Por su parte, Davis $(1991,1999)$ ha realizado una espeluznante descripción de los procesos en que se alimentan recíprocamente valorización económica, remodelación urbana y control del territorio en la futurista y degradada metrópoli de Los Ángeles. Por último, merece la pena resaltar las investigaciones en economía urbana de Sassen (1997) basadas en el concepto de "ciudad global".

Otra las consecuencias de la mercantilización de las relaciones sociales y del influjo de los criterios valorizantes ha sido las repercusiones en alguna de las diferenciaciones conceptuales que habitualmente se manejan. Tal es el caso de la distinción entre aquello que es productivo y lo que es improductivo. En este sentido, de acuerdo con el concepto clásico de Marx, trabajo productivo es aquel que genera plusvalor, que valoriza, e improductivo el que no. Sin embargo, no cabe duda de la existencia de profundísimas diferencias entre el capitalismo del "laissez faire" del siglo XIX o incluso el capitalismo oligopólico del siglo XX y, por otra parte, el funcionamiento macro y microeconómico del capitalismo financiarizado y tecnológico del siglo XXI, uno de cuyos efectos radica en que pone en tela de juicio aquella dicotomía. En efecto, con la extensión de la ley del valor a través de la circulación de capital

6 Trabajadores cuyo salario está por debajo de lo que la estadística oficial considera línea de la pobreza. Sobre esto, como algo que refleja el grado de demencia a que ha llegado el mundo del laboral del siglo XXI, se ha podido constatar, según el Informe 2004 de la OIT, que la mitad de los trabajadores del planeta tienen un salario inferior a dos euros diarios. 
a todas las esferas del circuito de la mercancía - monetarización de las relaciones sociales abarcando desde la producción a la reproducción, se difumina la frontera entre lo productivo y lo improductivo. Y, aunque es cierto que no toda actividad u operación laboral valoriza, si que el conjunto del circuito integral - en que el capital circulante pasa a desempeñar un papel primordial(acortamiento del tiempo de circulación, aceleración del ciclo económico y de la rotación mediante las TIC y las nuevas formas organizativas) - queda sojuzgado por el productivismo. En este sentido, un aspecto relevante del marco postfordista y neofordista es que la ley del valor y los criterios productivistas se convierten en elementos que configuran las estructuras y procesos sociales, incluidos el Estado - el Estado interioriza la ley del valor y los vínculos y organismos supraestatales.

Por otro lado, una característica de la producción integral es la adaptación permanente a las oscilaciones del mercado para garantizar el aumento y la realización del valor. Esto se logra al posibilitar que las distintas secuencias del circuito de la mercancía: financiación, adquisición de materias primeras, diseño, planificación, fabricación, comercialización etc. evolucionen en permanente interrelación con el entorno - como "máquinas comunicativas" - lo que hace que se genere información convertible en conocimiento que es "conocimiento valorizante", operativo, imprescindible para efectuar los ajustes y modificaciones pertinentes. Por otra parte, la organización interna de los procesos pone de manifiesto la utilización generalizada de técnicas de ingeniería social: grupos de trabajo, equipos multidisciplinares, sesiones grupales de "brainstorming", "benchmarking", etc...cuyo desarrollo se apoya, en gran parte, en la inversión y el trastocamiento, metabolización, de formas de cooperación surgidas en los episodios y en los ciclos de lucha precedentes. Un aspecto particular de estas dinámicas es la importancia creciente que adquiere el "sistema de innovación" en el trabajo postfordista. En este sentido, si observamos lo acontecido con el trabajo en este ámbito comprobaremos que la realidad ha superado las expectativas que limitaban la innovación a la inversión tecnológica en la modalidad de capital fijo o en $\mathrm{I}+\mathrm{D}+\mathrm{i}$ (Investigación + Desarrollo + innovación). Sobre este particular, la innovación postfordista, es decir, el uso de sistemas telemáticos y de autómatas, así como el recurso a técnicas de organización implicativas han convertido en funcionales aspectos del comportamiento humano como la socialidad y el lenguaje que se nutren del saber social acumulado.

La extensión de la axiomática valorizante al conjunto de las fases del circuito de la mercancía prefigura, por tanto, un circuito, símil de movimiento perpetuo - "ciclo integrado de la mercancía" - que abarca un sinfín de prácticas. A este respecto, el "modelo Benetton" en el que la producción y circulación de capital se generan flujos interactivos con el entorno de saber e información (mediante encuestas, estudios de mercado etc. que retroalimentan a modo de "concurrent engineering" el diseño industrial y la comercialización de productos) constituye un ejemplo paradigmático de este enfoque que concibe el circuito de la mercancía como flujo de sinergias en un ecosistema concreto.

Con todo, algo que resulta sumamente significativo, particularmente en las áreas centrales de capitalismo - territorio "metrópoli" - es que, en relación con esta dinámica inédita en que se ha producido un salto cualitativo en las formas modalidades de fagocitación de cuerpos y subjetividades, en esa indistinción entre productivo e improductivo, las sinergias y flujos que finalmente conducen a la valorización sobrepasan los límites de la empresa y del trabajo para difundirse por el territorio. Ello quiere decir que estas sinergias y flujos cuya finalidad es la generación de excedente dependen no únicamente del trabajo productivo, sino de un sin fin de comportamientos y relaciones que están ahí, en el territorio; aglutinan: costumbres, formas de relación, valores, "cultura cívica". Agrupan una serie amplia de elementos y flujos que valorizan y de prerrequisitos valorizantes. Esto significa, en definitiva, que la lógica de la valorización - la secuencia D - M - D' - parasita las "formas de vida", se instala en la vida social y en las instituciones, en la esfera de la producción y en la 
reproducción (sanidad, enseñanza, vida cotidiana...), lo que provoca que sus efectos se prolonguen más allá del trabajo y de los límites formales (los que fija el derecho mercantil) de la empresa. Podemos afirmar, a este respecto, que la producción integral se despliega en forma de bucle, esto es: el sistema industrial se despliega como megamáquina productora de objetos tangibles e intangibles, pero sobre todo, como generadora de subjetividad social mercantilizada; y, a su vez, dicha subjetividad alimenta el circuito de la mercancía. La resultante de todo esto es que en este periodo-espacio/tiempo de la "metrópoli" monetarizada - el trabajo muta en los ámbitos postfordistas en cooperación social productiva, y la "sociofactoría" reemplaza a la fábrica fordista y taylorista.

En suma, estas serían de manera sucinta las características básicas del postfordismo:

a) Surge como respuesta fundamental a la conflictividad derivada de la "centralidad obrera";

b) Se perfila como la modalidad tecno-productiva y de organización que define la estrategia de las corporaciones en el capitalismo contemporáneo;

c)Se combina con otras modalidades que categorizamos en líneas generales como neofordismo, pero en su articulación juega un papel determinante;

d) La ciencia, la técnica y distintas modalidades de saber social se delinean como el principal soporte de la valorización;

e) Estos cambios recurren a las Tecnologías de la Información y la Comunicación (TIC), a los diseños en red y a la "ingeniería psicosocial";

f) La mutación del trabajo que engloba al trabajo cognitivo se desparrama por el territorio en forma de trabajo social cooperante.

Es preciso insistir, una vez más, en que estas dinámicas no comportan la abolición de modalidades productivas anteriores, sino que, por el contrario, lo que se prefigura es una cartografía compleja - regida desde el punto de vista estratégico por sistemas tecnológicos y organizacionales "high tech" - en la que se engarzan secuencias, unidades productivas y sectores postfordistas y procedimientos fordistas y taylorista redefinidos.

\section{Superar el "general intellect"}

En este apartado trataremos con un mayor detalle algunos aspectos específicos de estos nuevos procesos, ante todo en lo concerniente a la vertiente postfordista. Sobre este tema, hay que señalar, de entrada, que a pesar de que en las diversas etapas en que la organización capitalista ha sido predominante siempre ha habido vínculos entre ciencia y sistema productivo, no obstante, lo que distingue al postfordismo respecto de los modos de producción anteriores es que en este caso el saber de la ciencia aplicada o tecnociencia queda totalmente absorbido por el circuito de la mercancía. Podríamos añadir como un aspecto concreto, aunque de gran relevancia, de estas transformaciones el papel desempeñado por la microelectrónica, el lenguaje y el enfoque implicativo de la organización. Pero, hay más. En realidad lo verdaderamente importante es que el postfordismo se desarrolla como "megamáquina" (Mumford, 1967, 2002) que metaboliza no sólo el saber de la ciencia y de la técnico, sino que además extiende sus redes hasta englobar distintas parcelas de saber social. A este respecto, Castells y May (1994) enfatizan la importancia del "medio innovador",

7 Castells y Hall han definido en Las tecnópolis del mundo, p. 30, “medio innovador" como sigue: “...sistema de estructuras sociales, institucionales, organizativas, económicas y territoriales que crean las condiciones para una generación continua de sinergias y su inversión en un proceso de producción que se origina a partir de esta capacidad sinérgica, tanto para las unidades de producción que son parte de este medio innovador como para el medio en su conjunto". 
sinónimo de entorno (social) denso en saberes operativos, condición indispensable del progreso económico. Resulta significativo también que desde la economía japonesa hayan surgido algunas voces con propuestas engañosas, como Matsui $(1998$, p. 93), que plantea, por lo que se refiere a la gestión del $\mathrm{I}+\mathrm{D}+\mathrm{i}$, abandonar conceptos "competitivos" que incluyen las nociones de "vencedor" y "vencido", y propugna adentrarnos en la "era de la concurrencia cooperativa".

Otro aspecto fundamental de estos saberes, en concreto de los que están ligados a los sistemas informacionales, es que son yacimientos inagotable de información y conocimiento y, además, que su coste de reproducción tiende a cero. Las consecuencias de esta situación en lo tocante a la visión "ortodoxa" de la economía, pero sobre todo para la discursividad crítica son de una importancia crucial. Con la telemática se derrumban algunos importantes postulados seculares, dogmas de la economía neoclásica, esto es, partir de la escasez de bienes y la "ley de los rendimientos decrecientes", cuando lo que sucede es exactamente lo contrario de lo que indican estos enunciados. En efecto, los costes para replicar y distribuir por las redes telemáticas estos saberes son casi nulos y, por otro lado, su expansión no reduce sino que aumenta las posibilidades para la producción ilimitada de riqueza. Esto contribuye, en cambio, como ha señalado Boutang (2004), a la agudización de ciertas contradicciones. Tal es el caso de la normativa que rige la protección de la propiedad intelectual, o mejor dicho, la privatización del saber (social), ya que si por un lado preserva, por otro bloquea el desarrollo del conocimiento al poner límites cada vez más estrictos a la libre circulación de ideas, o bien porque antepone el derecho de propiedad privada al de difusión y utilización públicos, colectivos, libres, del saber existente. Esta problemática ha adquirido tal magnitud que ha conseguido dividir a las propias multinacionales.

Así pues, en este contexto, la fascinación que ejercen los sistemas técnológicos dispositivos hiperreales - ha contribuido a enmascarar aspectos fundamentales que tienen que ver con el funcionamiento y con los efectos de dichos sistemas. Sobre este particular, destaca el hecho de que la ciencia, la técnica y ciertos saberes menos estructurados emergen, en determinadas tareas, segmentos y sectores del circuito integrado de la mercancía como uno de los pilares del engranaje económico. En este sentido, el modelo de "sociedad del conocimiento" o de "sociedad TIC" tiene que ver con aquellas concepciones, es decir, con la idea de que el saber provinente de la ciencia y de la técnica, la intensidad tecnológica, disponer de fuerza de trabajo cualificada, un sistema educativo de calidad, son requisitos indispensables para el desarrollo económico y, en general, que favorecen el bienestar de la población. Es así como esta imagen feliz y falaz encubre que tales saberes constituyen un parte esencial de un escenario muy concreto: la "metrópoli"del capital. Aquí, el conocimiento en sus diversas modalidades más o menos sistemáticas $(\mathrm{I}+\mathrm{D}+\mathrm{i} \ldots)$, el que procede de la experiencia en el puesto de trabajo o, desde otro ángulo, el saber adquirido a través de la socialidad, constituyen, desde aquella perspectiva, ingredientes para alimentar el circuito de la mercancía y para asegurar la gobernabilidad.

Un análisis pormenorizado de este enfoque permite vislumbrar que la noción de conocimiento utilizada se refiere exclusivamente al saber capaz de contribuir de un modo u otro - a través de esa mezcla de trabajo y "colaboración ciudadana" - a la producción y reproducción del nexo capitalista. No se trata, por tanto, de un saber inocuo. Se trata, de un saber que está en el meollo de los intercambios económicos, y cuyo valor se cuantifica, gradúa, en términos monetarios, de cantidades de dinero con arreglo a una axiomática de la acumulación, en el marco del plusvalor y de la ley del valor instaurados por el poder políticoeconómico. Efectivamente, si partimos de que el postfordismo tiene su apoyatura en saberes diversos, en un espectro que va del saber tecno-científicos hasta el saber social difuso, saber práctico reciclado, saber social desmercantilizado y mercantilizado, que, una vez metamorfoseados, cristalizan y operan en las máquinas y en la organización, en formato material e inmaterial (conceptos, procesos, esquemas epistémicos y metodológicos etc.), 
sucede que el valor-tiempo de trabajo en esta modalidades, al depender de intangibles, imposibilita la medida objetiva, puesto que: icómo medir la creatividad y la cooperación piezas clave del postfordismo? Esto origina que el algoritmo y la ley del valor se desplieguen, en el paso del trabajo vivo al valor y al dinero - la cuantificación (y lo cualitativo, el nexo) como pura imposición; mero instrumento de dominio que pone de relieve, por este motivo, su carácter de proceso eminentemente político, de poder. La relación entre poder y saber se manifiesta ahora con absoluta nitidez.

Sobre este particular, el concepto de "general intellect" - intelecto general o social en forma de saber científico objetivado en las máquinas - definido por Marx en los "Cuadernos Grundrisse", destaca con antelación la función de la ciencia como soporte del sistema económico. Con arreglo a estas concepciones, una de las consecuencias del salto tecnológico dependiente de la expansión del "general intellect" tenía que haber sido que, al erigirse la ciencia o para ser exactos la ciencia aplicada, tecno-ciencia, en fuerza productiva de primer orden, el trabajo directo del obrero, por lo que se refiere a la valorización, iba a quedar relegado inexorablemente a un segundo plano. Literalmente:

Una vez incluido en el proceso de producción del capital, el instrumento de trabajo recorre, sin embargo, diferentes metamorfosis, la última de la cuales es la "máquina", o mejor dicho, un "sistema automático de máquinas" (sistema de máquinas; el sistema automático sólo es la forma más acabada y más adecuada del mismo, que es el único que transforma la máquina en un sistema) puesto en movimiento por una fuerza motriz autómata, que se mueve a sí misma; este autómata se compone de numerosos órganos mecánicos e intelectuales, de forma tal que los trabajadores mismos son determinados como miembros conscientes del mismo (Marx, 1978, vol. 2, p. 81).

Asimismo, en el periodo actual, según la prognosis de Rifkin (1997), el cambio tecnológico tendría que comportar ineluctablemente en un tiempo no muy lejano la práctica desaparición del trabajo. Sin embargo, a pesar del valor parcialmente predictivo de algunas de estas afirmaciones, sucede que el trabajo rutinario, monótono, que exige un importante esfuerzo físico y psíquico, sigue siendo todavía algo patente y muy extendido, aunque también somos conscientes de que los nuevos sistemas tecnológicos (informáticos, robóticos, redes), encierran un enorme potencial de reducción del tiempo de trabajo y, por consiguiente, de sustitución de fuerza de trabajo.

Estos procesos, que requieren un clima innovador, prolífico, se nutren del saber social, pero desbordan, en este aspecto, la esfera estricta de la ciencia y de la técnica, de los saberes sistemáticos del tipo $\mathrm{I}+\mathrm{D}+\mathrm{i}$ y de las habilidades codificadas. En los segmentos y en las aplicaciones postfordistas ya no basta con ejecutar complejos protocolos, ni con la rutina del gesto o del movimiento repetido una y otra vez. Se precisa algo más, a saber: lograr que la "ciudadanía", una parte de la cual posee las características de neoproletariado polivalente, se involucre, sea maleable, sumisa pero a la vez activa, dentro y fuera del trabajo, lo que permitirá, finalmente, alcanzar la "excelencia social" en competitividad.

Una de las consecuencias de la diseminación del saber o conocimiento valorizante es, también, que espacio/tiempo de trabajo/empleo y espacio/tiempo de no empleo aparecen en múltiples casos solapados al delimitar un espacio/tiempo global/concreto, circuito integral de la mercancía, en el que se fagocitan los comportamientos y las "formas de vida". La productividad social, que incluye las "formas o estilos de vida" (costumbres, gustos estéticos, lenguaje, actitudes), en el postfordismo toma el relevo de lo que fue el trabajo fordista y taylorista; emerge como pieza clave del espacio/ tiempo global/concreto del capital, el cual, en la vertiente socioeconómica, toma la forma de "sociofactoría".

Llegados a este punto, dedicaremos nuestra atención al lenguaje, al que debe considerarse uno de los principales elementos del conocimiento valorizante, de la relación 
entre conocimiento y valorización, y en general, del engranaje postfordista. Podemos sacar a relucir aquí que la microelectrónica, el lenguaje y la socialidad han sido los tres soportes de la producción en la "era postmoderna". Sin embargo, es necesario aclarar que el ámbito del lenguaje en el postfordismo no se ciñe solamente a los juegos de lenguaje y lógicos reconocidos; de hecho los desborda para abarcar distintas y complejas modalidades expresivas y de comunicación social que, en determinados casos, cuajan en secuencias del circuito de la mercancía.

Para comprender porqué decimos que las atribuciones y los usos del lenguaje van más allá de las funciones preestablecidas y sistemáticas, de los lenguajes artificiales, es preciso poner de relieve la existencia de un principio básico del postfordismo que denominaremos de "sobre-implicación", y que tiene sus antecedentes en los círculos de calidad" y en las técnicas "kaizen" de "mejora continua" del toyotismo. Los requerimientos de las nuevas modalidades productivas exigen que haya dinámicas de "feedback" entre el circuito de la mercancía y su entorno, lo que convierte a la encuesta en prototipo y matriz de la multiplicidad de interrelaciones, indicativo de que, a diferencia del fordismo, que, como decía Virno (2001b, 2003), transcurre en silencio, en el postfordismo la comunicación es indispensable Esta comunicación engloba una amplia gama de situaciones: desde las sinergias en los equipos multidisciplinares, en los grupos de trabajo (GTs) y las aportaciones al "sistema de innovación" hasta las interrelaciones con la demanda y con el entorno. Finalmente todos estos de flujos de información son algoritmizados y convertidos en conocimiento valorizante; reducción de complejidad que tiene un coste, ya que al simplificar deja fuera, pierde todo aquello que no se ajusta a la norma canónica y, debido a esto, en realidad estos procesos se despliegan de manera reduccionista y contradictoria al bloquear el despliegue de la riqueza potencial o imaginable.

En relación con estas cuestiones, Marazzi $(2002,2003)$ ha acuñado el concepto "máquinas lingüísticas" para referirse al papel del lenguaje en el trabajo postfordista; esto es:

Cuando se dice que, con el postfordismo, la comunicación entra en la producción, que se convierte en un factor directamente productivo, se emplaza al "lenguaje", que, por vocación, está en la base de la comunicación. La "coincidencia" entre el acto de producción y el acto de comunicación en el nuevo paradigma productivo abre un abanico de problemas de análisis del lenguaje tan fascinante como de extrema complejidad y densidad (2003, p. 19).

En otro párrafo añade, detallando más esta lectura:

Dado que el postfordismo (...) ya no separa la producción de la comunicación, sino que hace de su coincidencia el acicate mismo del desarrollo económico, lo primero que hay que comprobar es de qué tipo de comunicación o, mejor, de qué tipo de lenguaje estamos hablando (...) Este tipo de lenguaje debe ser lo más formal posible, es decir, debe tratarse de un lenguaje hecho de símbolos, signos y códigos "abstractos", condición indispensable para permitir que todos los que colaboran en el seno de la empresa puedan interpretarlos al instante, sin titubeos. En la abstracción, en la "artificialidad" del lenguaje, reside la posibilidad, para una fuerza de trabajo en continuo movimiento (...) de comprender dicho lenguaje y, por consiguiente, de utilizarlo para responder a las "órdenes" que la información comunica (2003, p. 19).

No obstante, lo que realmente ocurre es que el postfordismo instrumentaliza no solamente los lenguajes formales reconocidos, utilizados por los saberes sistemáticos, sino que extiende su influjo para incluir otro tipo de lenguajes y formas expresivas que han sido objeto de atención de la lingüística pragmática y de la etnometodología. En estos enfoques no se habla de signos, sino de sistemas de significación, de texto, de discurso, lo que implica que al aludir al lenguaje y a la comunicación capturada por las relaciones económicas y de poder, lo 
que incluye las dinámicas intersubjetivas que operan en la red o en los "grupos de trabajo" habrá que tener en cuenta no únicamente palabras y frases, sino también otro tipo de lenguajes (no verbal, gestual etc.); dimensión transfrástica del lenguaje. Se trata, por tanto, de abordar el papel del lenguaje en el postfordismo desde la consideración de los usos del lenguaje, más que en términos de "competencia gramatical" o de "competencia lingüística" como prácticas social, "competencia modal", en virtud de la cual el sujeto/objeto recurre a un conjunto de "modalidades compatibles": manejo de reglas, reconocimiento del contexto, consecución de fines, etc...que son parte de del "hacer", de las prácticas expresivas, verbales o no verbales, en las distintas interrelaciones.

\section{Subsunción múltiple en la sociofactoría}

En este apartado procederemos al desglose de los procesos que afectan a esa parte básica de $\mathrm{P}$ que es la fuerza de trabajo y el trabajo, que, finalmente, se extienden por la "sociofactoría", en el marco de la "metrópoli monetarizada". Podemos representar estas trasformaciones de manera escueta como sigue: subsunción formal-subsunción realsubsunción múltiple. Así pues, si tomamos como punto de referencia el Capítulo VI inédito del Libro I de El Capital (2001), veremos que la absorción o subsunción - inserción de un elemento nuevo en una estructura global más amplia - por el capital del trabajo y del proceso laboral se realiza a partir de un proceso laboral previo que ha sido conformado en base a otros procesos y condiciones de producción anteriores. El proceso laboral preexistente en este caso podría ser el trabajo artesanal o el trabajo del agricultor minifundista. Además, los cambios que sufren estas modalidades previas de trabajo se realizan subsumidos por el capital. En la subsunción por el capital basada en un "modo de trabajo preexistente", es decir, con un determinado desarrollo de la fuerza productiva y con la modalidad de relación laboral que le corresponde, únicamente se puede obtener plusvalor con la prolongación de la jornada de trabajo, por lo que el resultado obtenido, trabajo excedente, es "plusvalor absoluto". A esta modalidad de producción de excedente o de producción de plusvalor Marx la conceptúa como "subsunción formal del trabajo en el capital". Dicha modalidad aparece en contraposición respecto de modalidades laborales anteriores, caso del artesanado, no absorbidas todavía por el modo de producción capitalista.

En una etapa posterior aparecen las "fuerzas productivas sociales" o el trabajo socializado a resultas de la implantación de la división del trabajo en el taller, y de la aplicación de la ciencia y la técnica con ciertos fines, así como del trabajo a gran escala. En estos procesos tan sólo el trabajo socializado puede utilizar los resultados o productos de aquellos saberes y, recíprocamente, aquellos saberes se sustentan necesariamente en cierto desarrollo del proceso material. La "fuerza de trabajo socializada" por oposición a la actividad laboral de los individuos dispersos junto a la aportación de la ciencia y la técnica prefiguran, así, globalmente, la "fuerza productiva del capital", o bien la "fuerza productiva del trabajo" si presuponemos que trabajo y capital son idénticos. En esta situación han sido transformadas radicalmente la producción y las fuerzas sociales del trabajo. A este respecto, si el "plusvalor absoluto" ejemplificaba la "subsunción formal" del trabajo por parte del capital, la producción del "plusvalor relativo" por esta "fuerza de trabajo socializada", en que el modo capitalista de producción opera como un "modo de producción "sui géneris", expresa lo que Marx cataloga

8 Con un enfoque interdisciplinar, que incluye desde la pragmática hasta la etnometodología y la sociología política, se han promovido distintas investigaciones que han puesto el acento, como se ha indicado al comienzo del articulo, en el lenguaje como práctica social, lo que ha generado una rica bibliografía de la que podemos entresacar algunas obras: Eco (1978), Greimas e Courtés (1979), Cicourel (1980), Dijk (2000, 2003), Martín e Whittaker (1998), Íñiguez (2003). 
de "subsunción real". Sin duda, se ha producido un cambio esencial consistente en que la "capacidad del trabajo social combinado" ha ocupado el lugar del obrero individual.

Con la tercera etapa este proceso desemboca en lo que conceptuamos de "subsunción múltiple", a saber: la fagocitación por el capital de la naturaleza multidimensional del individuo y de las interrelaciones sociales (cognición social, redes asociativas, dimensión emotiva, lenguaje, socialidad, saber) en el marco de las trasformaciones económicas (y políticas) y tecnológicas de las últimas tres décadas, neo/postfordistas. Esta denominación permite poner de relieve que ha habido un salto cualitativo en las formas de subsunción real y, más en concreto, en las modalidades de generación de excedente y de gobierno. Una de las características de estos cambios que afectan a los sistemas tecnológicos y a las formas organizativas han comportado, de facto, la implantación de flujos y dispositivos de captura que no pueden se categorizados ni como "trabajo social combinado" enunciado en "El Capital", ni tampoco como "general intellect", intelecto general de naturaleza básicamente tecno-científica. La complejidad de aquellos procesos suponen un grado de penetración y manejo de los comportamientos y de la subjetividad, micro y macrosocial, inéditas. En este sentido, tal vez lo más significativo de la producción integral y de la "sociofactoría" es que lo que resulta de estos procesos - configuración del "mind body process" - más que mercancías concretas, tangibles e intangibles, son "prototipos de comportamiento". Procesos subordinados finalmente al objetivo de la acumulación que englobamos bajo el concepto de "subsunción múltiple".

Este escenario no es, sin embargo, un escenario de equilibrio. Las contradicciones se agudizan de manera exorbitante debido a que la multidimensionalidad de las formas de explotación acrecientan el carácter heterónomo del trabajo, que, de algún modo, ocupa los comportamientos y la psique, y por el rechazo hacia este tipo de relaciones. En el aspecto Desde el punto de vista psicosocial y de la salud destaca la aparición de trastornos y patologías vinculados precisamente a las relaciones laborales y tecnológicas implantadas. Sobre este particular, Ehrenberg ha remarcado la vertiente social de la depresión alimentada por el stress competitivo; esto es:

La depresión comienza a afirmarse en el momento en que el modelo disciplinar de gestión de los comportamientos, las reglas de autoridad y de conformidad según las prohibiciones que establecían las clases sociales y a los sexos un destino se ha derrumbado frente a las normas que incitan a cada uno a la iniciativa individual ordenándole devenir el mismo. A causa de esta nueva normatividad, la entera responsabilidad sobre nuestra vida pasa a depender de cada uno de nosotros. La depresión se presenta entonces como una enfermedad originada por una responsabilidad en la que domina el sentimiento de insuficiencia. El depresivo no está a la altura de las circunstancias, está agotado de devenir sí mismo (2000, p. 10).

La etiología de este síndrome estaría ligada a lo que podemos catalogar de sobreimplicación, hiper-implicación. Por su parte, Berardi (2001, pp. 75-77) se ha referido también al "síndrome pánico depresivo", que incluye dos patologías: depresión y pánico, detectado en las últimas décadas como un efecto de la lógica de la competitividad, mercantilizada. Síndrome ligado a la ideología de la autorrealización y al "imperativo felicista", al postulado deseante del aquí y ahora del consumo, de la realización del valor. No cabe duda, se aduce, de que este comportamiento en un contexto no competitivo, ni productivista, ni individualista, no se manifiesta como patología; sin embargo, en un clima competitivo, de "ganadores" y "perdedores", en que no se acepta el fracaso, este comportamiento es interpretado en clave psicopatológica; y, además, no hay competencia sin derrota y, por otro lado, la norma social no admite el error como algo normal, puesto que ello supondría poner en entredicho los fundamentos ideológicos y de eficiencia. A este respecto, la considerable adicción a los psicofármacos sería, pues, la otra cara de este "fin de la historia". 
Por último, como algo específicamente relacionado con internet y con el trabajo en red, Turkle (1997) ha detectado ciertos cuadros que denotan una estructura psíquica disociada que categoriza de "síndrome de personalidad múltiple". Según esta autora, dicho síndrome tiene que ver con la distorsión de ciertos procesos que se dan en la práctica diaria consistente en que algunos usuarios interpretan las "ventanas" como metáfora que les hace ver al yo como un "sistema múltiple" que se fragmenta y reparte entre varios escenarios en los que representan diversos papeles; encarnan diversos personajes; consiste en un "yo descentrado" que se mueve en distintos mundos y desempeña, a modo de "identidades paralelas", diversos "yo".

Así pues, analizar el proceso de trabajo en la "sociofactoría" nos ha permitido conceptuar las características de la subsunción en el neo/postfordismo, es decir, la "subsunción múltiple". A este respecto, Virno (2001) sostiene, al referirse a la captura de capacidades por la maquinaria postfordista, que en su historicidad, esta modalidad supone el retorno de una antropogénesis según la cual el "homo sapiens" debe ser considerado como no especializado, lo que conlleva el rechazo de su categorizaciónen tanto que "homo faber", aspecto este que es aprovechado por el postfordismo para configurar lo social como proletariado polivalente, multifuncional. En cualquier caso, es necesario subrayar que en el nuevo marco las relaciones sociales y el territorio, condición necesaria de la reproducción ampliada y cuyo relieve muestra las huellas de las sucesivas transformaciones socioeconómicas y tecnológicas, aparecen enhebrados por criterios productivistas y de valorización, dependientes de la racionalidad analítica financiera del "economic value added" (EVA). Hay que precisar, sin embargo, sobre este particular, que a pesar de que la tendencia dominante es promover la productividad general de lo social, no obstante, ni todas las secuencias son valorizantes y, además, se producen fugas y disfunciones relacionados con la vulnerabilidad de los sistemas tecnológicos y de la organización, pero también por los comportamientos explícitas y por las prácticas soterradas de rechazo de estos procesos heterodeterminados. En este sentido, lo realmente interesante para la perspectiva crítica no es tanto averiguar que secuencias valorizan, producen plusvalor, y cuales no, ello significaría que todavía estamos presos del objetivismo economicista y hegeliano, sino desarmar la ley del valor, antes nexo de poder que relación económica, su dispersión por lo social y por el territorio, para examinar la gama de comportamientos, resistencias, antagonismo que en este medio se generan, así como la verosimilitud de la apertura de espacios desmercantilizados y desterritorializados.

Este escenario sin parangón - basculando entre la crisis y la catástrofe - pone de manifiesto, por tanto, que en la "subsunción múltiple" intervienen diversidad de factores que van más allá de lo que ha sido la simple instrumentalización de habilidades y conocimientos sistemáticos, perfectamente codificados. La subsunción de las prácticas y de las relaciones sociales, en particular aquellas que tienen que ver con lo que ha sido analizado por la pragmática y por la etnometodología, reconducidas hacia la racionalidad mercantilizante, permite sostener que la acumulación ampliada neo/postfordista se nutre de multitud de ingredientes: patrones de conducta, códigos, costumbres, símbolos, esquemas epistémicos, imaginario, etc...que son parte del bagaje cultural y del orden simbólico vigentes. En estos procesos el nexo capitalista se expande a partir de la captura de materiales preexistentes, procesos descritos por Harvey (2004) como "acumulación por desposesión", y que no finalizan con lo que fue la originaria "acumulación primitiva". Esto es, por el contrario, algo que ha persistido a lo largo del tiempo. De manera significativa, las características básicas de aquella "acumulación primitiva" se han mantenido hasta la actualidad y han delineado una "geografía histórica del capitalismo".

Por otra parte, el papel desempeñado por el Estado en calidad de soporte e inclusive de actor político-económico, así como la transformación experimentada por la ley del valor debido a la crisis del trabajo industrial y a la abstracción creciente del trabajo mutado, 
incluida la producción inmaterial, hacen que en la depredación de requisitos y prerrequisitos de acumulación lo político, el poder, acabe por determinar la valorización.

Así, al tomar en consideración las formas concretas que adopta la subsunción en la "sociofactoria" - porción de la "metrópoli" - al ahondar en la naturaleza heterodeterminada del trabajo, donde la ley del valor ha devenido ley de mando que se inscribe en un sistema axiomático impuesto, mero poder, de ello se deduce que el ojo deconstructivo tiene situar en el centro del análisis la política, el poder, y no la economía, a pesar de no deja de ser una tarea insoslayable en un mundo regido por la lógica calculística y economicista disponer de un saber acerca de los procesos económicos neo/postfordistas.

Podemos afirmar, pues, que la genealogía del trabajo indica que en el trabajo, ahora trabajo social o cooperación social productiva, subyace siempre una relación de poder; el trabajo es ante todo relación de poder en la medida en que es sujeción, nexo imperativo. En este sentido, el núcleo de la valorización, de la producción y reproducción ampliada, vínculo productor de plusvalor, se apoya en una proporción, problemática, que es la que existe entre trabajo necesario y trabajo excedente. Sin embargo, hay algo más, y es que esta relación y estos procesos están determinados, o mejor, constituidos, puesto que de lo contrario serían inviables, por una relación de poder que en la "sociedad del trabajo" es poder disciplinar, panóptico, y, posteriormente, en la "metrópoli", poder que controla, moldea, fagocita, involucra. Sobre este particular, no es posible omitir que Braudel (1979) puso de manifiesto la consideración del capital como forma de poder.

Por otra parte, hay que decir que en la "metrópoli" la relación capital-trabajo, que nunca ha dejado de ser relación de poder, y, por tanto, política, ahora, liquidado el "pacto social", desarticulado el contrapoder representado por la centralidad obrera, dicha relación se muestra de manera ostensible como asimetría, puro y simple poder, sin mediaciones, adialéctico. Poder sobre cuerpos y subjetividades que embebe lo social. Pero también poder de Estado que toma la forma, como ha señalado Agamben (2003), de "Estado de excepción", guiado por una lógica bélica que opera de manera selectiva, crea subespacios en que se despoja al sujeto/objeto de casi todo, un ser que con absoluta impunidad es convertido en un no ser, a la manera de las colonias y de los "lager" hebreos o de Guantánamo.

Por fin, pensamos que para terminar este texto haremos referencia a un espléndido fragmento de Clastres, en el que, a sabiendas de que el tiempo histórico es irreversible, no hay vuelta atrás, no por ello dejan de ser muy sugerente para definir el vínculo existente entre economía, cultura y política; muestra de una interpretación perfectamente diferenciada de productivismo y economicismo tan en boga. Concepción, la de aquel autor, que contrasta con la consideración del trabajo, aunque sea en forma de "trabajo vivo", como límite y potencia, y que tiene su apoyatura en una visión del trabajo como invariante, cuyas raíces remiten a la modernidad de la "Aufklärung", en el siglo XVIII. Así, Clastres, al comentar la obra de Marshall Sahlins y, concretamente, la cuestión de la centralidad o no de la economía, sostiene:

Nos enseña (Sahlins) o nos recuerda que en las sociedades primitivas la economía no es una "máquina" de funcionamiento autónomo: es imposible separarla de la vida social, religiosa, ritual, etc. No sólo el campo económico no determina el ser de la sociedad primitiva, sino que es más bien la sociedad la que determina el lugar y los límites del campo económico. No sólo las fuerzas productivas no tienden a desarrollarse, sino que, además, la voluntad de sub-producción es inherente al "modo de producción doméstico". La sociedad primitiva no es el juguete pasivo del juego ciego de las fuerzas productivas, sino que, por el contrario, es la sociedad la que ejerce sin cesar un control riguroso y deliberado sobre su capacidad de producción. Lo social regula el juego económico; en última instancia, lo político determina lo económico. Las sociedades primitivas son "máquinas" de antiproducción (1981, p. 151). 
Como quiera que sea, estas nociones nos dan pistas para un tratamiento distinto de la subsunción monetarizante de las formas de vida contemporáneas y, en particular, del trabajo neo/postfordista. De entrada, es preciso dejar bien sentado, una vez más, que la "centralidad del trabajo", el propósito de articulación del contrapoder y del discurso crítico en torno al eje capital-trabajo, ha pasado a la historia, es únicamente una experiencia que pertenece a un periodo de la memoria histórica de la luchas obreras. Sin duda, con la derrota y posterior implantación del neo/postfordismo - en la "sociofactoría" y en "metrópoli" - lo social ha perdido la homogeneidad y masividad que habían caracterizado a las grandes concentraciones fabriles, esos polvorines que alimentaron la radicalidad "obrerista". Además, los sistemas tecnológicos (telemática, robótica etc.; "lean production", "lean management", ingeniería simultánea etc.) utilizados en áreas y sectores concretos del capitalismo intensivos en tecnología, pero no en fuerza de trabajo, con una enorme capacidad de reducción de la demanda de trabajadores, combinado con la precarización sociolaboral, hacen, en conjunto, que el recurso del trabajo como hilo conductor del conflicto/antagonismo, arma contra el capital, haya perdido gran parte de su anterior potencial.

En esta tesitura, se originan también otros efectos que contribuyen a exasperar las contradicciones del proceso productivo integral, como ocurre con las disfunciones causadas por los comportamientos desafectos, la no identificación con las tareas, o simplemente el cinismo, estrechamente ligados a la degradación de las relaciones sociolaborales y todo lo que acarrea la monetarización del nexo social instaurada por las relaciones de producción y por la circulación del capital. A ello podemos añadir otro tipo de problemáticas debidas al carácter estructural interdependiente, reticular, global y local, del capitalismo mundial, lo que incrementa de manera inusitada la existencia de puntos débiles, caso de la logística (almacenamiento, trasporte) y de las redes telemáticas de la industria y de las finanzas (fondos de inversión, mercado de divisas; servicios: auditorias, consulting etc.), donde la posibilidad de colapso, avería, falsificación (dinero electrónico; ante todo, porque: ien qué consiste y dónde está el "objeto real", el referente del significante o del "speech act", en un mundo virtualizado, de la abstracción del trabajo, impregnado de nihilismo?) del circuito de la mercancía, accidentalmente o, porqué no, causada por los trabajadores, es algo perfectamente factible y muy probable, y sus consecuencias económicas son de enorme gravedad. El caso del dinero electrónico ejemplifica a la perfección esta escenografía, ante todo porque : ien qué consiste y dónde está el "objeto real", el referente al que apunta el significante o el "speech act" en un mundo hiperreal, virtualizado, de la extrema abstracción del trabajo y con un trasfondo fuertemente nihilista?

En definitiva, lo que muestra estas operaciones de desarme de las formas de "subsunción" es que el trabajo muta de manera ambivalente. Si por una parte introduce sistemas tecnológicos y organizativos que incorporan saberes que engloban aspectos cognitivos, lingüísticos y emocionales que posibilitan reducir el aporte de la fuerza de trabajo a una fracción mínima; por otra, en cambio, se extiende para abarcar amplias franjas de lo social, se torna "sustancia común". En este contexto, "subsunción múltiple", se explicita como nunca que la fuerza de trabajo, el trabajo, antes que valor de cambio o como sobredeterminación de su naturaleza mercantilizado, en un estrato más profundo, es relación de poder; sociedad de mentes prefabricadas (Minsky, 1985); dominio inédito, complejo, producción tecnológica de cuerpos y subjetividades. La regulación valorizante ha devenido ley política que se nutre de la interrelación. Ley impuesta por un poder que no es solamente poder de Estado, sino también y muy especialmente poder microfísico, biopoder actualizado que se articula en torno a "dos polos de desarrollo": uno, "centrado en los cuerpos máquina", disciplinar, que ha operado como "anatomopolítica del cuerpo humano"; otro, que aparece después, cuyo objetivo son los "cuerpos-especie", donde se considera que el cuerpo es soporte de procesos biológicos, mecánica de la vida, y que agrupa una serie de intervenciones calificadas como "biopolítica de la población" (Foucault, 1980, p. 168). Las implicaciones de esta interpretación son, ciertamente, decisivas, y comportan, de inmediato, postular un no a 
la subsunción múltiple, en versión asalariada o no. El trabajo ni escasea ni es un "bien social". Cosa distinta, cualitativamente distinta, aquello que está implícito en la negación, es lo que categorizamos como "actividad autodoterminada" (Quintana, 2003) - contraposición adialéctica - que abarca un heterogéneo espectro de disfunciones y antagonismos (rechazo del trabajo, espacios desmercantilizados, discontinuidades cooperantes, insumisión). Desde este punto de vista, la praxis crítica, ¿imprevisible? iautovalorizante? inada? sitúa en el punto de mira no únicamente el trabajo como el valor de cambio que valoriza sino, sobre todo, el trabajo neo/postfordista, la subsunción de los comportamientos y "estilos de vida" en tanto que piezas del engranaje de la "gubernamentalización" de lo social.

\section{Referencias}

Adamic, L. (1984). Dynamite. A Century of Class Violence in America. London: Rebel Press.

Agamben, G. (2003). Stato di eccezione. Torino: Bollati Boringhieri.

Aglietta, M. (1979). Regulación y crisis del capitalismo. Madrid: Siglo XXI.

Alquatti, R. (1977). Rapporto sulla Fiat. Milano.

Arendt, H. (2001). La condición humana. Barcelona: Paidós.

Berardi, F. (2001). La fabbrica dell'infellicità. New economy e movimento del cognitariato. Roma: Derive Approdi.

Bologna, S. (1978). La tribú delle talpe. Milano: Feltrinelli.

Braudel, F. (1979). Civilisation matérielle, économie et capitalisme s. XV-XVIII siécles, Vol. 3. Paris: Armand Colin.

Burr, V. (1997). Introducció al construccionisme social. Barcelona: Proa.

Castells, M. \& Hall, P. (1994). Las tecnópolis del mundo. La formación de los complejos industriales del siglo XXI. Madrid: Alianza Editorial.

Castoriadis, C. (1988). Los dominios del hombre: las encrucijadas del laberinto. Barcelona: Gedisa.

Cicourel, A. (1980). Three models of discourse analysis: the Role of social structures. Discourse Process, $3,18-30$

Clastres, P. (1978). La sociedad contra el Estado. Caracas: Monte Ávila Editores.

Clatres, P. (1981). Investigaciones en antropología política. Barcelona: Gedisa.

Clastres, P. (1986). Crónica de los indios guayaquis. Barcelona: Altafulla.

Coriat, B. (1982). El taller y el cronómetro. Ensayos sobre el taylorismo, el fordismo y la producción en masa. Madrid: Siglo XXI.

Davis, M. (1991). City of quartz. London: Verso.

Davis, M. (1999). Geografia della paura. Los Angeles: l'immaginario collettivo del disastro. Milano: Feltrinelli.

Deliri, M. et al. (2004). Barcelona, marca registrada. Barcelona: Virus.

Dijk, T. A. van (2000) (eds.). Estudios sobre el discurso, vol. 2. Barcelona: Gedisa.

Dijk, T. A. van (2003). Ideología y discurso. Barcelona: Ariel.

Dos Passos, J. (1983). U.S.A. 3 vols. Barcelona: Bruguera.

Eco, U. (1978). Tratado de semiótica general. Barcelona: Lumen.

Ehrenberg, A. (2000). La fatigue d'être soi. Paris: Odile Jacob. 
Ellul, J. (2003). La edad de la técnica. Barcelona: Octaedro.

Feyerabend, P. (1981). Tratado contra el método. Madrid: Tecnos.

Foucault, M. (1979). La arqueología del saber. México: Siglo XXI.

Foucault, M. (1980). La voluntad de saber. Historia de la sexualidad, Vol. 1. Madrid: Siglo XXI

Gaudemar, J. P . (1981). La movilización general. Madrid: La Piqueta

Gorz, A. \& Marglin, J. (1977). (Orgs.). Crítica de la división del trabajo. Barcelona: Laie.

Greimas. A. J. \& Courtés, J. (1979). Semiotique. Paris: Hachette.

Guerrero, D. (1997). Historia del pensamiento económico heterodoxo. Madrid: Trotta.

Harvey, D. (1995). L'acumulation flexible par l'urbanisation: réflexions sur le "post-modernisme" dans la grande ville americaine. Futur antérieur, 29.

Harvey, D. (1998). La condición de la postmodernidad. Buenos Aires: Amorrortu.

Harvey, D. (2000). Spaces of hope. Edinburgh: Edinburgh University Press.

Harvey, D. (2004). El nuevo imperialismo. Madrid: Akal.

Íñiguez, L. (2003). (Org.). Análisis del discurso. Barcelona: UOC.

Latour, B. \& Woolgar, S. (1988). La vie de laboratoire. La production des faits scientifiques. Paris: Éditions La Découverte.

Latour, B. (1992). Ciencia en acción. Barcelona: Labor.

Matsui, K. et al. (1998). Made in Japan. L'industrie japonaise au tournant du siècle. Paris: Librairie Générale Française.

Marazzi, C. (2002). Capitale $\mathcal{E}$ linguaggio. Roma: Derive Approdi.

Marazzi, C. (2003). El sitio de los calcetines. El giro lingüístico de la economía y sus efectos sobre la política. Madrid: Akal.

Martín, L., Whittaker, R. (1998). Poder-decir o el poder de los discursos. Madrid: Arrecife/UAM.

Marx, K. (1972). El Capital, Vol. 1. Madrid: EDAF.

Marx, K. (1974). Teorías sobre la plusvalía. Buenos Aires: Cartago.

Marx, K. (1978). Líneas fundamentales de la crítica de la economía política. Grundisse, Vol. 2. Barcelona: Crítica.

Marx, K. (2001). El Capital. Libro 1. Capítulo VI (inédito). México: Siglo XXI.

Matsui, K. et. Al. (1998). Made in Japan. Lindustrie japonaise au tournant du siècle. Paris: Librairie Générale Française.

Méda, D. (1998). El trabajo. Barcelona: Gedisa.

Minsky, M. (1985). The society of Mind. New York: Simon \& Schuster.

Moulier, Y. et. al. (2004). Capitalismo cognitivo. Madrid: Taficantes de Sueños.

Mumford, L. (1967). The myth of machine. Hartcourt: Brace and World.

Mumford, L. (1982). Técnica y civilización. Madrid: Alianza Editorial.

Mumford, L. (2002). La megamáquina. Barcelona: Colección con Otros.

Naredo, J. M., Bermejo \& R. Offe, C. (1997). ¿Qué crisis? Retos y transformaciones de la sociedad del trabajo. Donostia: Gakoa.

Negri, A. (1979). Marx oltre Marx. Quaderno di lavoro sui Grundisse. Milano: Feltrinelli.

Negri, A. \& Hardt, M. (2003). El trabajo de Dionisos. Madrid: Akal. 
Noble, D. F. (1984). Forces of production. A Social History of Industrial Automation. New York: Oxford University Press.

Noble, D. F. (2001). La locura de la automatización. Barcelona: Alikornio.

Quintana, F. (1992). Para una caracterización epistémica y metodológica de las ciencias sociales. Papers, 39, 101-116.

Quintana, F. (2002a). Fetichismo tecnológico y política. Archipiélago, 51, 130-139.

Quintana, F. et. al. (2002b). Asalto a la fábrica. Barcelona: Alikornio.

Quintana, F. (2003). Trabajo, neuromagma y fisuras. Athenea Digital , 3. Artigo disponível na internet: http://antalya.uab.es/athenea/num3/quintana.pdf

Rifkin, J. (1997). El fin del trabajo. Barcelona: Paidós.

Roth, K. H. (1979). Autonomia e classe operaia tedesca. Milano: Feltrinelli.

Sahlins, M. (1983). Economía de la Edad de Piedra. Madrid: Akal.

Sassen, S. (1997). Le città nell'economia globale. Bologna: Il Mulino.

Tronti, M. (2001). Obreros y capital. Madrid: Akal.

Turkle, S. (1997). La vida en la pantalla. La construcción de la identidad en la era de Internet. Barcelona: Paidós.

Virno, P. (2001). Charla y curiosidad: "la formación difusa" en el postfordismo. Archipiélago, 48, 66-72.

Weber, M. (1993). La ética protestante y el espíritu del capitalismo. Barcelona: Península.

Woolgar, S. (1991). Ciencia: abriendo la caja negra. Barcelona: Anthropos.

\section{Endereço para correspondência}

fqcastello@yahoo.es

Recebido em: 01/03/2005

Pareceres enviados em: 27/08/2005

Revisão recebida em: 30/11/2005

Aprovado em: 29/01/2006 


\section{Cadernos de Psicologia Social do Trabalho}

\section{Pedido de assinatura e de exemplares avulsos}

Para fazer uma assinatura ou solicitar qualquer exemplar avulso, envie-nos a ficha abaixo preenchida e cheque nominal ao Instituto de Psicologia - USP. Por gentileza, escreva ou telefone para saber os valores atuais de cada exemplar ou da assinatura.

Centro de Psicologia Aplicada ao Trabalho

Av. Prof. Mello Moraes, 1721

Bloco D, sala 163

Cidade Universitária, São Paulo/ SP

05508-030

Endereço eletrônico: cpat@usp.br

\begin{tabular}{|l|l|c|c|}
\hline Quantidade & \multicolumn{1}{|c|}{ Pedido } & \multicolumn{1}{|c|}{ Valor $^{*}$} & \multicolumn{1}{|c|}{ Total } \\
\hline & volume 1 & esgotado & esgotado \\
\hline & volume 2 & & \\
\hline & volume 3/4 & & \\
\hline & volume 5 & & \\
\hline & volume 6 & & \\
\hline & $\begin{array}{l}\text { volume 7 } \\
\text { volume 8 }\end{array}$ & & \\
\hline & volume 9, número 1 & Total: R\$ \\
\hline & assinatura por dois anos (quatro exemplares) & & \\
\hline & & & \\
\hline
\end{tabular}

" Por favor, consultem-nos a respeito dos valores antes de fazer seus pedidos.

\begin{tabular}{|c|c|c|}
\hline Nome: & & \\
\hline Endereço: & & \\
\hline & & CEP: \\
\hline Cidade: & & Estado: \\
\hline Telefone: ( ) & E-mail: & \\
\hline Data: / / & Assinatura: & \\
\hline
\end{tabular}

